\title{
Aprovechamiento de Sangre Ovina para la Elaboración de un Sustituto de Empanizador
}

\author{
Verónica Pelcastre ${ }^{\text {a,* }}$, Sandra Ramírez ${ }^{\text {a }}$, Eduardo A. Cruz a ${ }^{\text {a }}$ Monserrat Hernández ${ }^{\text {a }}$, Ana K. Ruíz a , Gabriela A. Vázquez ${ }^{\text {b }}$ \\ a Alumnos de la Licenciatura de Química en Alimentos, Área Académica de Química, Universidad Autónoma del Estado de Hidalgo. \\ ${ }^{b}$ Profesora Investigadora del Área Académica de Química.
}

\section{Resumen}

La sangre contiene un alto nivel proteico y aminoácidos esenciales que podrían ser benéficos en la dieta humana. Sin embargo, en México, este residuo de los rastros municipales suele arrojarse a ríos o lagos cercanos sin ningún tratamiento previo, lo cual evidentemente es un foco de contaminación. Una alternativa para disminuir la contaminación que generan los residuos del sacrificio de animales es utilizarlos para la obtención de otros productos. En este proyecto se propuso la elaboración de un producto tipo empanizador a base de harina de sangre y plasma sanguíneo adicionado con trigo y especias. El producto obtenido demostró la viabilidad del aprovechamiento de este tipo de residuos alimentarios.

Palabras Clave: valorización de residuos, rastros, sangre ovina, agroindustria.

\section{Introducción}

Los desechos de las agroindustrias son un problema ambiental tanto por su volumen como por sus altos contenidos de sólidos y de nutrientes (carbono, nitrógeno y fósforo, entre otros). Cuando se les descarga en el medio ambiente pueden generar gases de efecto invernadero (como $\mathrm{CH}_{4}$ y $\mathrm{N}_{2} \mathrm{O}$ ), o bien producir eutrofización y anoxia en los cuerpos acuáticos. En particular, se considera que las industrias empacadoras y procesadoras de carne son las que tienen el mayor potencial contaminante de todo el giro alimentario (Kroyer, 1995). No obstante, más allá de verlos como fuentes de contaminación, los residuos que estas industrias producen se pueden utilizar para generar energía, composta, piensos animales e incluso materias primas y nuevos productos (Uicab y Sandoval, 2003).

Tanto en el Estado de México como en el Estado de Hidalgo existe una alta producción de ganado ovino; de hecho, ocupan el primer y segundo lugar a nivel nacional, respectivamente (SIAP, 2017). Comúnmente el sacrificio de animales se hace en rastros ya sean TIF (Tipo Inspección Federal) o municipales, pero también se llega a hacer "tras patio"; este último no es autorizado por las instituciones correspondientes. Durante el proceso de sacrificio se realiza el sangrado y la evisceración, y dado que la mayoría de los rastros y pequeños productores no aprovechan en su totalidad la sangre que se genera, esta se descarga directamente al alcantarillado. Lo anterior ocasiona una gran contaminación. Por ejemplo, una descarga de estos residuos podría causar una DBO de $200,000 \mathrm{mg} \mathrm{O}_{2} / \mathrm{L}$ aproximadamente (Bonilla et al., 2006), cantidad que supera ampliamente los límites máximos permisibles por la NOM-001SEMARNAT-1996.

\footnotetext{
*Autor en correspondencia.

Correo electrónico: vero.pelfra@gmail.com
}

En el año 2009 se pudieron haber recuperado en el mundo 138 millones de toneladas de sangre proveniente de ovinos, caprinos, aves, bovinos y porcinos. Sin embargo, solo 5.76 millones de toneladas de sangre de ovinos y caprinos se pudo recuperar, en comparación con un 54.54 millones de toneladas de sangre en aves. La sangre recuperable de ovinos y caprinos es marginal frente a la de otras especies (bovinos, porcinos y aves), ya que corresponde al $4 \%$ del total de sangre recuperable en el mundo (Ballesteros et al., 2014a).

La sangre es una fuente de proteínas de alto valor nutricional. No obstante, su principal deficiencia radica en la baja cantidad de isoleucina, un aminoácido raramente limitante en la mayoría de los cereales, por lo que una mezcla de sangre y algún cereal proporcionaría una proteína de alto valor biológico (Ballesteros et al., 2014b). Por lo anterior, surgió la idea de incorporar trigo a productos derivados de la sangre ovina para compensar dicha deficiencia.

Es por ello que en este trabajo nos propusimos obtener un producto en el cual se aproveche la mayor cantidad de sangre ovina, y no se destine únicamente a la preparación de los platillos típicos que se consumen actualmente (como la fritanga o la moronga). El producto fue un sustituto de empanizador, que se elaboró a partir de harina de sangre y de plasma sanguíneo; en este último caso, el objetivo era mejorar las propiedades sensoriales de la harina de sangre, que se caracteriza por un color oscuro y un ligero sabor metálico. El análisis sensorial de los productos se llevó a cabo tras emplearlos para recubrir pechuga de pollo. 


\section{Materiales y Métodos}

\subsection{Obtención de Sangre}

Se trabajó con sangre de ovino obtenida del rastro municipal de Zumpango, Estado de México. Para evitar la coagulación del material biológico se adicionó EDTA al 1\% (100 mL por cada litro de sangre) y se mantuvo a temperatura de refrigeración $\left(4^{\circ} \mathrm{C}\right)$ durante su traslado al Área Académica de Química.

\subsection{Obtención de Sustitutos}

Para obtener los sustitutos de empanizador a base de harina de sangre y de plasma se siguieron las metodologías que se muestran en las Figura 1 y 2, respectivamente.

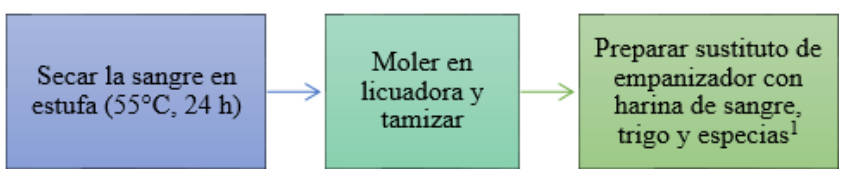

Figura 1. Obtención de sustituto de empanizador a base de harina de sangre. ${ }^{1}$ Harina de sangre (100 g), sémola de trigo (50 g), especias: pimienta, laurel, mejorana y orégano $(2 \mathrm{~g})$.

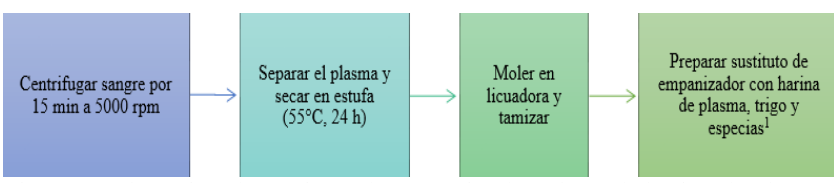

Figura 2. Obtención de sustituto de empanizador a base de harina de plasma. ${ }^{1}$ Harina de plasma sanguíneo (100 g), sémola de trigo (50 g), especias: pimienta, laurel, mejorana y orégano $(2 \mathrm{~g})$.

\subsection{Incorporación del Sustituto}

Para la incorporación del producto a la pechuga de pollo, esta se sumergió en huevo y posteriormente se cubrió por completo con el sustituto de empanizador. Previamente se calentó aceite en una sartén y se cocinaron las piezas de pollo (2.5 minutos de cada lado). Finalmente se retiró el exceso de grasa con una toalla de papel. Se siguió la misma metodología para ambos sustitutos.

\subsection{Evaluación Sensorial}

La evaluación se llevó a cabo con alumnos y profesores del ICBI; participaron 50 jueces no entrenados ( 28 hombres y 22 mujeres) de entre 18 y 55 años de edad. Para la evaluación sensorial, se troceó la pechuga de pollo (previamente cocinada) en piezas de $2 \times 2 \mathrm{~cm}$ aproximadamente y fueron colocadas sobre platos desechables. Posteriormente se les proporcionó una ficha (Figura 3) a los panelistas, así como una pieza de la muestra para que emitieran su evaluación. Se realizó la prueba para ambos sustitutos (Figura 4).

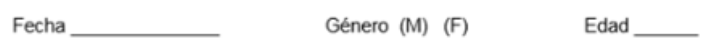

Para la muestra recibida marque con una $(\mathrm{x})$ sobre la escala según su aceptación.

Me gusta mucho

Me gusta ligeramente

Ni me gusta ni me disgust

Me disgusta ligeramente

Me disgusta mucho

Comentarios

Figura 3. Ficha de cata. Adaptada de Espinosa (2007).

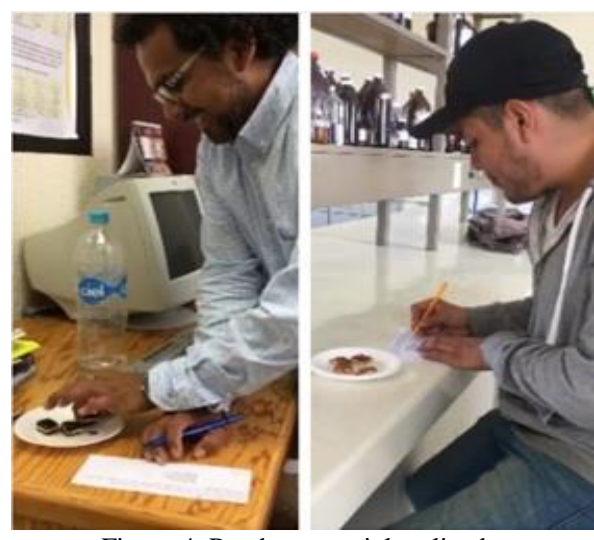

Figura 4. Prueba sensorial realizada.

\section{Resultados y Discusión}

Se obtuvo harina de sangre y harina de plasma según lo detallado en las figuras 1 y 2 , respectivamente. Las características de ambas harinas, principalmente el color, fueron diferentes, ya que la harina de sangre presentó un color marrónrojizo brillante (Figura 5a), mientras que la harina de plasma tuvo un color beige (Figura 5b). Ambas harinas se combinaron con especias y sémola de trigo para obtener un sustituto de empanizador. Posteriormente, los sustitutos se usaron para recubrir pechuga de pollo, que se cocinó por freído.

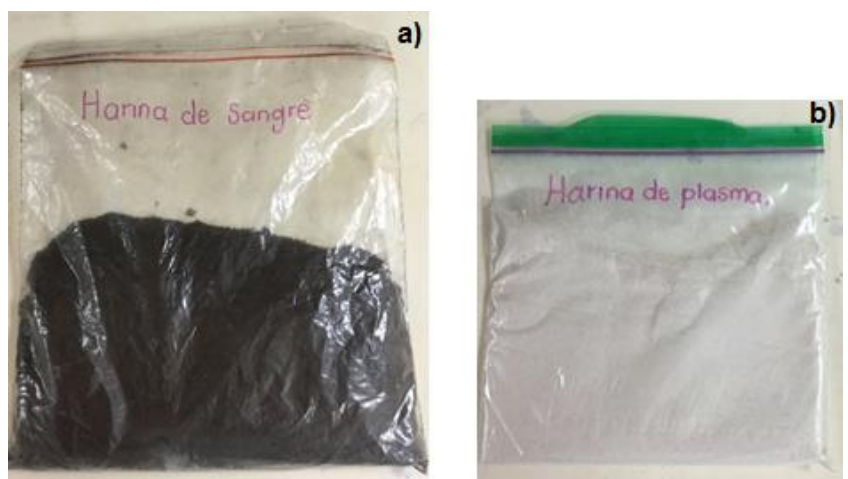

Figura 5. a) Harina de sangre y b) Harina de plasma obtenidas.

Respecto a la evaluación sensorial realizada, en la prueba hedónica del sustituto de empanizador a base de harina de sangre, el $60 \%$ de la población evaluada manifestó que le gustó mucho el producto, al $20 \%$ le gustó ligeramente, al $14 \%$ le fue indiferente, mientras que a un $6 \%$ le disgustó ligeramente. En cuanto a la mezcla a base de harina de plasma, al $40 \%$ le gustó mucho, al $34 \%$ le gustó ligeramente, al 16\% le fue indiferente el producto y al resto (10\%) le disgustó ligeramente.

Estos resultados contradijeron la idea inicial de que el producto a base harina de plasma sería más aceptado por su similitud con un empanizador convencional, y que el producto a base de harina de sangre sería rechazado por su color y sabor intensos. Sin embargo, ocurrió lo contrario, y el recubrimiento de harina de sangre resultó ser más aceptado por los consumidores, por ser de un color poco usual, llamativo y con buen sabor. En cambio, el producto a base de plasma sanguíneo no aportó mucho sabor al pollo, a decir de los panelistas. 


\section{Conclusión}

Se logró obtener los productos esperados (sustitutos de empanizador a base de harinas de sangre y de plasma), y se concluyó que el sustituto a base de harina de sangre tuvo mayor aceptación. Con lo anterior se puede observar que es factible el uso de residuos de la industria cárnica para el desarrollo de nuevos productos y así aumentar su sustentabilidad.

\section{English Summary}

\section{Use of ovine blood for the preparation of a coating mix}

\section{Abstract}

Blood contains a high level of protein and essential amino acids that could be beneficial in the human diet. However, in Mexico, this waste of slaughterhouses is often dumped into nearby rivers or lakes without any previous treatment, which is evidently a source of pollution. An alternative to reduce the pollution generated by animal slaughter residues is to use them to obtain other products. In this project the development of a type of coating mix based on blood flour and blood plasma mixed with wheat and spices was proposed. The obtained product demonstrated the viability of the valorization of this kind of agroindustrial waste.

\section{Keywords:}

Waste valorization, slaughterhouses, ovine blood, agroindustry

\section{Referencias}

Ballesteros N. N., Sánchez G. J., Pérez G. J. y Macedo S. L. (2014a). La sangre animal en el mundo. Departamento de Biología Molecular y Biotecnología, Instituto de Investigaciones Biomédicas, UNAM.

Ballesteros N. N., Sánchez G. J., Pérez G. J. y Macedo S. L. (2014b). Potencial nutricional del uso de la sangre animal recuperable en el mundo. Departamento de Biología Molecular y Biotecnología, Instituto de Investigaciones Biomédicas, UNAM.

Bonilla M., Civit S. y Signorini M. (2006). Evaluación de riesgos sanitarios. Residuos aplicados a rastros. Sistema Federal Sanitario-COFEPRIS.

Espinosa J. (2007). Evaluación sensorial de los alimentos. Ed. Universitaria, La Habana, pp. 83-84.

Kroyer G. T. (1995). Impact of food processing on the environment-an overview. Food Science and Technology, 28(6), 547-552.

SIAP (2017). Avance por producto. Obtenido de Servicio de Información Agroalimentaria y Pesquera: http://infosiap.siap.gob.mx/repoAvance_siap_gb/pecAvanceProd.jsp

Uicab B. L. y Sandoval C. C. (2003). Uso del contenido ruminal y algunos residuos de la industria cárnica en la elaboración de composta. Tropical and Subtropical Agroecosystems, 2(2), 45-63. 